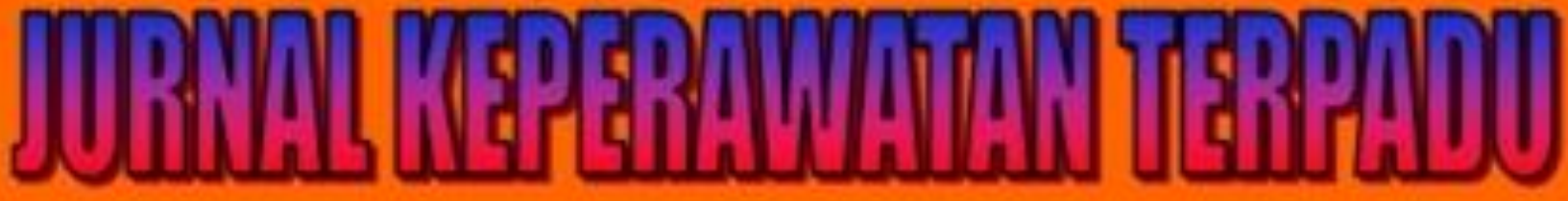

\section{Integrated Nursing Journal}

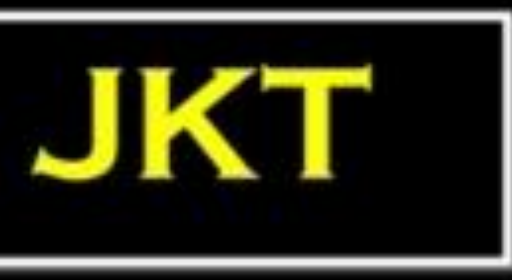

\section{p-ISSN: 2406-9698 (Print) e-ISSN: 2685-0710 (Online)}

\section{Vol. 2 No. 1 April 2020}

\section{KEMENTERIAN KESEHATAN RI}

\section{POLTEKKES MATARAM JURUSAN KEPERAWATAN}

Jalan Kesehatan V/10 Mataram NTB - http://jkt.poltekkes-mataram.ac.id 


\section{Vol. 2 No. 1 April 2020}

\section{Editorial Team}

\section{Editor-in-Chief}

Moh. Arip, Jurusan Keperawatan Poltekkes Kemenkes Mataram, Indonesia

\section{Editorial Board}

1. Mr. Frans Judea Samosir, Universitas Prima Indonesia, Indonesia

2. Baiq Kirana Kitna, Jurusan Keperawatan, Poltekkes Kemenkes Mataram, Indonesia

3. Irwan Budiana, Jurusan Keperawatan, Poltekkes Kemenkes Kupang, Indonesia

4. dr. Baskoro Tri Laksono, RS. Biomedika Mataram, Indonesia

5. Sitti Rusdianah, Jurusan Keperawatan, Poltekkes Kemenkes Mataram, Indonesia

6. Mira Utami Ningsih, Jurusan Keperawatan, Poltekkes Kemenkes Mataram, Indonesia

\section{Alamat Redaksi:}

Jurusan Keperawatan Mataram Poltekkes Kemenkes Mataram Kampus B

Jl. Kesehatan V No.10 Pajang Timur-Mataram NTB-Indonesia, 83127

Telepon: +62 370-621383

Fax: +62 370-631160

Email: jurnalkeperawatanterpadu2019@gmail.com

Laman: http://jkt.poltekkes-mataram.ac.id/index.php/home/index 


\section{Vol. 2, No. 1, April 2020}

\section{DAFTAR ISI}

Pengaruh Self Hypnosis Terhadap Respon Cemas Mahasiswa

Pada Ujian Tahap Akhir Program Di STIKes Buana Husada Ponorogo

Yudha Anggit Jiwantoro, Afifa Ika Kridawati, Danies Tunjung Pratiwi

Efektifitas Tepid Water Sponge Terhadap Penurunan Suhu Tubuh Pada Anak Dengan Masalah Keperawatan Hipertermia: Studi Kasus

Emy Mulyani, Nur Eni Lestari

Perilaku Pencegahan Penyakit Tidak Menular Pada Remaja Ambon

Hamdan Hariawan, Martini Tidore, Greeny Z. Rahakbau

Pengetahuan dan Sikap Perawat Berhubungan dengan Pelaksanaan Patient

Safety

Elisa Sulistia Fitri, Kusnanto, Herdina Maryanti

Efektivitas Art Therapy terhadap Pengetahuan dan Praktik Pemeliharaan Kesehatan Gigi pada Anak Usia Prasekolah

Linda Widyarani, Wiwi Kustio Priliana, Cecilya Kustanti

Konsep Diri Remaja Yang Mengalami Bullying

Puji Lestari, Liyanovitasari

Pengaruh Senam Tai Chi Terhadap Peningkatan Kualitas Tidur Lansia Di Balai Sosial Lanjut Usia Mandalika

Fathaillah Liestanto, Dina Fitriana

Hubungan Komunikasi Terapeutik Perawat Dengan Tingkat Kecemasan

Pasien Hemodialisa Di RSUD Dr Harjono Ponorogo

Ervan Nur Cholis, Rumpiati Rumpiati, Ike Sureni

Upaya Mengatasi Nyeri Post Op Sectio Cesaria Melalui Foot Massage Therapy Diruang Nifas RSUD Kota Mataram

Masadah, Cembun, Ridawati Sulaeman

Peningkatan Pemberdayaan Keluarga Melalui PINKESGA (Paket Informasi Keluarga) Kehamilan Dalam Mengambil Keputusan Merawat Ibu Hamil Mardiatun, Dewi Purnamawati, Ely Mawaddah
Page

$1-6$

Page

$7-14$

Page

$15-21$

Page

22-28

Page

29-39

Page

40-46

Page

$47-53$

Page

54-63

Page

$64-70$

Page

$70-78$ 


\title{
Efektivitas Art Therapy terhadap Pengetahuan dan Praktik Pemeliharaan Kesehatan Gigi pada Anak Usia Prasekolah
}

\author{
Linda Widyarani ${ }^{1}$, Wiwi Kustio Priliana ${ }^{2}$, Cecilya Kustanti ${ }^{3}$ \\ ${ }^{1,2,3}$ Progtam Studi DIII Keperawatan, Sekolah Tinggi Ilmu Kesehatan Notokusumo Yogyakarta, Indonesia
}

\begin{abstract}
ABSTRAK
Latar belakang: Art therapy merupakan salah satu strategi dalam upaya promosi kesehatan yang efektif diaplikasikan pada anak-anak. Salah satu art therapy yang efektif diterapkan pada anak-anak adalah terapi seni dengan mewarnai gambar dan bercerita atau mendongeng. Art therapy mempermudah anakanak mempelajari hal-hal baru dan menciptakan suasana belajar yang menyenangkan. Art therapy dapat menggiring anak-anak memahami mekanisme sebab akibat secara rasional. Pembelajaran pada anak dengan art therapy bermedia mewarnai gambar dan bercerita atau mendongeng dapat diaplikasikan sebagai upaya promosi kesehatan dalam meningkatkan pengetahuan dan praktik anak-anak tentang pemeliharaan kesehatan gigi. Penelitian ini bertujuan untuk mengetahui pengaruh art therapy terhadap pengetahuan dan praktik pemeliharaan kesehatan gigi pada anak usia prasekolah. Metode: Desain penelitian ini adalah quasi eksperiment dengan one group pre-post test design. Teknik pengumpulan data adalah total sampling. Responden pada penelitian ini adalah anak-anak usia prasekolah yaitu usia 4-6 tahun. Variabel independent pada penelitan ini adalah art therapy, sedangkan variabel dependent adalah pengetahuan dan praktik pemeliharaan kesehatan gigi pada anak usia prasekolah. Instrument penelitian adalah kuesioner, checklist, alat peraga berupa phantom gigi, sikat gigi, pasta gigi, media gambar dan oil pastel. Analisis data menggunakan uji wilcoxon. Hasil dan Analisis: Terdapat perbedaan yang bermakna $(p=0,000)$ antara pengetahuan responden sebelum dan sesudah pemberian art therapy dengan metode bermain mewarnai gambar dan bercerita atau mendongeng. Terdapat perbedaan yang bermakna $(p=0,000)$ antara praktik pemeliharaan kesehatan gigi sebelum dan pemahaman sesudah pemberian intervensi. Kesimpulan: Art therapy terbukti efektif meningkatkan pengetahuan dan praktik pemeliharaan kesehatan gigi pada anak usia prasekolah.
\end{abstract}

Kata kunci: Art Therapy, Anak Prasekolah, Pemeliharaan Kesehatan Gigi

\section{The Effect of Art Therapy on Knowledge and Practice Dental Health Maintenance of Preschool Children}

\begin{abstract}
ABSTACT
Indroduction: The use of arts interventions in preschool children is beneficial and an effective way of promoting health behavior. Health promotion can improve children's health and well being. One of techniques used in art therapy can include drawing, painting, coloring and also therapeutic storytelling to help child express themselves artistically. The intention of art therapy is to help children use art as a way to explore and communicate feelings and to work through the issues, and also promote an atmosphere positive and fun learning. Art therapy had also been to help children explore the effects and causes mechanisms of dental health maintenance, rationally. The purpose of this research was to know the effect of art therapy including painting or coloring activities and also storytelling on dental health maintenance of preschool children. Methode: Research design used in this study is quasi experimental research design with quantitative approach. The one group pre-post test design involves this research. In this research, the total numbers of 28 preschool children ( $4-6$ years) were randomly selected by total sampling. The independent variables were art therapy and the dependent variable was dental health maintenance of preschool children. The data were collected by questionnaire and were analyzed by wilcoxon test. Result and Analysis: The results showed that there were enhancement for
\end{abstract}


knowledge and practice of dental health maintenance toward the experimental group. These data were strengthened by the result of Wilcoxon Test statistical analysis that showed the significant differences for knowledge $(p=0,000)$ and practice of dental health maintenance $(p=0,000)$. Conclusion: It can be concluded that dental health maintenance education using modified art therapy including painting or coloring activities and also therapeutic storytelling effected the dental health maintenance's knowledge and practice changes for preschool age children. The suggestion for the further experiment is to give regular health education using art therapy including painting or coloring activities with addition of observation for action of toothbrushing at home to obtain more accurate result.

Keyword: Art therapy, Preschool children, Dental Health Maintenance

\section{PENDAHULUAN}

Art therapy adalah sebuah proses penggunaan media seni dalam intervensi terpeutik. Art therapy adalah teknik untuk membangun hubungan interpersonal dengan anak-anak, menggunakan media seni yang kreatif akan membantu anak-anak dalam belajar dan memahami sesuatu secara optimal. Fokus terapi ini tidak secara khusus pada manfaat estetika pembuatan seni namun pada kebutuhan terapi agar anak dapat mengekspresikan dirinya. Art therapy dapat digunakan untuk membantu anak-anak, baik dengan setting individual, keluarga maupun kelompok. Art therapy membantu anak-anak belajar dan mengekspresikan apa yang mungkin sulit diterima dan diungkapkan dengan kata-kata serta membantu anak-anak berkomunikasi tentang isu dan masalah yang relevan secara cepat sehingga mempercepat penilaian, pemahaman dan intervensi (Hidayat, 2018). Hannigan et al (2019) memaparkan bahwa art therapy merupakan salah satu strategi dalam upaya promosi kesehatan yang efektif diaplikasikan pada anak-anak. Art therapy dapat merangsang kemampuan imajinatif non verbal anak-anak dan melalui terapi ini anak-anak juga dapat mengekspresikan perasaan dan emosi mereka sesuai dengan yang mereka rasakan. Art therapy juga efektif meningkatkan kepercayaan diri anak-anak dan juga mampu menciptakan komunikasi yang positif dan interaktif. Art therapy sangat cocok diterapkan di lingkungan sekolah maupun prasekolah, yang dapat diaplikasikan melalui seni musik, drama, gerak tari, bercerita atau mendongeng, menggambar dan mewarnai (visual art) serta seni digital (digital atau media art).

Penggunaaan aktivitas seni menggunakan metode menggambar dan mewarnai (visual art) dalam aktifitas terapi dilakukan berdasarkan asumsi bahwa jarang sekali terdapat resistensi pada penggunaan gambar sebagai bentuk komunikasi, terutama pada anak-anak serta memberi kesempatan anak mengekspresikan perasaan dan pikirannya dengan cara yang baru. (Alvina dan Kurnianingrum, 2018). Salah satu art therapy yang efektif diterapkan pada anak-anak adalah terapi seni dengan mewarnai gambar. Pada anak usia prasekolah, yaitu usia 4-6 tahun sudah mempunyai kemampuan mewarnai dengan rapi dan dengan warna yang merata, serta mampu mengkombinasikan warna, hal ini karena pada dasarnya kegiatan menggambar dan mewarnai sangat disukai dan dinikmati oleh anak-anak (Shofiyah, 2013). Selain dapat mengurangi tingkat stress dan kecemasan, mewarnai gambar merupakan terapi seni 
yang kreatif untuk meningkatkan komunikasi pada anak prasekolah, dan mewarnai gambar memberikan kesempatan anak usia 4-6 tahun bebas berekspresi (Debora et al., 2012). Arini (2016) menjelaskan bahwa upaya promosi kesehatan melalui media mewarnai gambar dapat meningkatkan tingkat pengetahuan dan perilaku hidup bersih dan sehat pada anak. Media pembelajaran melalui teknik mewarnai gambar dapat meningkatkan antusiasm anak-anak, sehingga materi pendidikan kesehatan dapat diberikan dengan menyenangkan dan tanpa paksaan.

Selain melalui media mewarnai gambar, art therapy juga efektif jika diberikan melalui metode bercerita atau mendongeng. Bercerita atau mendongeng merupakan proses terapeutik yang berpengaruh positif dan efektif terhadap kemampuan anak-anak usia prasekolah dalam memahami pembelajaran, bercerita atau mendongeng mempermudah anak-anak mempelajari hal-hal baru dan menciptakan suasana belajar yang menyenangkan. Bercerita atau mendongeng juga dapat menggiring anak-anak memahami mekanisme sebab akibat secara rasional (Brouzos et al, 2016). Isik (2016) menambahkan bahwa bercerita atau mendongeng memberikan dampak positif terhadap perkembangan kognitif anak. Kegiatan ini lebih efektif dan akan lebih memperluas pengenalan objek apabila saat mendongeng juga menggunakan alat peraga misalnya buku cerita bergambar, sehingga anak bisa melihat bentuk dari tokoh yang diceritakan dalam dongeng tersebut. Selain itu, dongeng juga dapat menambah wawasan, melalui kisah-kisah dongeng, anak mendapatkan berbagai informasi dan anak juga dapat mempelajari sebab akibat serta belajar menganalisa. Metode mendongeng juga membentuk pemikiran anak menjadi lebih baik, lebih kritis dan cerdas, anak juga bisa memahami hal-hal mana yang boleh dan tidak boleh ditiru. Bercerita atau mendongeng juga efektif mengembangkan daya imajinasi anak, meningkatkan ketrampilan berbahasa dan membangkitkan minat baca anak. Bercerita atau mendongeng juga membentuk retensi pengetahuan yang lebih baik sehingga anak-anak mempunyai memori yang tajam terhadap pembelajaran yang dilakukan. Pembelajaran dengan metode bercerita atau mendongeng memerlukan pemanasan terlebih dahulu dari guru/pendamping atau orangtua, misalnya dengan bertanya dan meminta anak-anak bercerita tentang pengalamannya terkait tema yang akan kita bahas. Vaahtoranta et al (2019) memaparkan hal yang sama bahwa bercerita atau mendongeng memberikan efek positif terhadap kemampuan daya ingat anak usia prasekolah. Bercerita atau mendongeng dengan intensitas 3 kali seminggu dengan tema yang sama, dapat meningkatkan daya ingat, meningkatkan kemampuan anak dalam menerima konsep/teori baru dan mampu merubah perilaku anak secara perlahan sehingga metode ini sangat disarankan diaplikasikan pada anak usia prasekolah, baik dirumah dengan pendampingan orangtua dan juga di sekolah dengan pendampingan guru. Bercerita atau mendongeng dapat dikombinasi dengan tokoh yang bervariasi sehingga meminimalisir kebosanan pada anak, meskipun dengan tema yang masih sama.

Pembelajaran pada anak dengan art therapy bermedia mewarnai gambar dan bercerita atau mendongeng dapat diaplikasikan sebagai upaya promotif dalam meningkatkan pengetahuan dan 
ketrampilan anak-anak tentang pemeliharaan kesehatan gigi. Masalah kesehatan gigi masih memerlukan perhatian, khususnya pada anak-anak. Masalah kesehatan gigi yang paling sering ditemukan pada anakanak, khususnya usia prasekolah adalah karies gigi (Eddy \& Mutiara, 2015). Hampir 90\% anak-anak usia prasekolah menderita karies gigi (Santik, 2015). Karies gigi atau gigi berlubang adalah penyakit jaringan keras gigi yang ditandai oleh rusaknya email dan dentin, disebabkan oleh aktivitas metabolisme bakteri dalam plak yang menyebabkan terjadinya demineralisasi akibat interaksi antar produk-produk mikroorganisme, ludah dan bagian-bagian yang berasal dari makanan dan email (Ramayanti \& Purnakarya, 2013). Gigi adalah jaringan tubuh yang sangat mudah rusak.

Pada anak-anak, penyebab kerusakan gigi antara lain malas untuk menyikat gigi, mengkonsumsi makanan manis dan lengket yang berlebihan, serta waktu menyikat gigi yang tidak tepat (Winnier et al, 2015). Anak-anak memang belum terbiasa sikat gigi secara rutin namun bukan berarti membiarkan gigi mereka tidak dibersihkan. Orangtua dan guru atau pendamping di lingkungan sekolah harus mengajarkan bagaimana cara menyikat gigi anak dengan benar, membiasakan dan memberi pengertian akan dampak buruk jika tidak menyikat gigi secara teratur. Makan makanan manis dan lengket yang berlebihan juga merupakan penyebab utama gigi berlubang pada anak-anak karena sisa-sisa zat gula yang menempel pada gigi mengundang bakteri yang dapat menghancurkan gigi (Kurniasih, 2018). Waktu menyikat gigi yang tidak tepat juga dapat menyebabkan kerusakan gigi. Kebiasaan anak-anak pada umumnya adalah menyikat gigi saat mandi, baik mandi pagi maupun sore padahal yang paling tepat adalah menyikat gigi setelah makan dan sebelum tidur (Ardani, 2018).

Penyebab utama timbulnya karies gigi pada anak adalah kebersihan gigi dan mulut (Eddy \& Mutiara, 2015). Karies gigi dapat dicegah dengan mengubah faktor penyebabnya, salah satunya adalah dengan pembersihan plak gigi (Elmitra, 2017). Secara mekanis, menghilangkan plak gigi dapat dilakukan dengan menyikat gigi menggunakan pasta gigi, ini adalah cara yang utama (Elmitra, 2017). Setiap orang dianjurkan untuk membiasakan diri menyikat gigi minimal dua kali sehari, pagi hari setelah makan dan malam hari sebelum tidur (Ardani, 2018). Kebiasaan ini dapat menghilangkan sisa makanan pada gigi dan mencegah pembentukan plak di gigi selama tidur sehingga menghambat akumulasi plak penyebab karies gigi (Triswari \& Pertiwi, 2017).

Berdasarkan studi pendahuluan melalui metode wawancara dengan anak-anak di PAUD Rosalinda, Canden, Kabupaten Bantul, Yogyakarta, diperoleh data bahwa 7 dari 10 anak mengatakan mereka terbiasa menggosok gigi dengan pasta gigi saat mandi pagi dan sore, sedangkan setelah sarapan dan sebelum tidur tidak pernah. Kadangkala hanya berkumur atau menggosok gigi tanpa menggunakan pasta gigi. Kebiasaan tersebut berisiko tinggi menyebabkan karies gigi, yang pada akhirnya menyebabkan pengapuran gigi. Dampaknya gigi menjadi keropos, berlubang bahkan patah. Karies gigi membuat anak mengalami kehilangan daya kunyah dan terganggunya pencernaan yang mengakibatkan pertumbuhan kurang maksimal (Widayati, 2014). Berdasarkan latar belakang tersebut, tujuan penelitian 
ini adalah mengetahui bagaimana efektivitas art therapy terhadap pengetahuan dan praktik pemeliharaan kesehatan gigi pada anak usia prasekolah.

\section{METODE}

Rancangan dan desain penelitian ini menggunakan metode quasi eksperiment dengan one group pre-post test design. Teknik pengumpulan data dilakukan dengan cara total sampling. Responden pada penelitian ini adalah anak-anak usia prasekolah yaitu usia 4-6 tahun. Pengetahuan dan praktik tentang bagaimana pemeliharaan kesehatan gigi responden diukur sebelum (pretest) dan sesudah (posttest) diberikan intervensi. Pengetahuan tentang bagaimana pemeliharaan kesehatan gigi responden dikaji menggunakan kuesioner dengan 15 item pertanyaan yang sudah dilakukan uji validitas dan reabilitas, sedangkan bagaimana praktik pemeliharaan kesehatan gigi responden dikaji menggunakan lembar checklist. Variabel independent pada penelitan ini adalah art therapy, sedangkan variabel dependennya adalah pengetahuan dan praktik pemeliharaan kesehatan gigi pada anak prasekolah.

Pada tahap awal, responden diminta menjawab pertanyaan sesuai kuesioner pengetahuan tentang pemeliharaan kesehatan gigi. Pengisian kuesioner difasilitasi oleh guru PAUD, yang kemudian responden juga diminta melakukan praktik pemeliharaan kesehatan gigi dan dinilai menggunakan lembar checklist. Pada tahap selanjutnya, responden diajak melakukan art therapy, yaitu bercerita atau mendongeng menggunakan buku cerita karya Widarahman (2019) dengan tema "Aku Bisa Menyikat Gigi Sendiri” dan dilanjutkan mewarnai gambar menggunakan oil pastel. Pada tahap akhir, responden diminta kembali menjawab pertanyaan-pertanyaan sesuai kuesioner pengetahuan tentang bagaimana pemeliharaan kesehatan gigi, pengisian kuesioner ini juga difasilitasi oleh guru PAUD, yang kemudian responden diminta kembali melakukan praktik pemeliharaan kesehatan gigi dan dinilai menggunakan lembar checklist. Dalam pemberian intervensi, media yang digunakan pada penelitian ini adalah alat peraga berupa phantom gigi, sikat gigi, pasta gigi, buku cerita, media gambar dan oil pastel. Analisis data menggunakan uji wilcoxon.

\section{HASIL PENELITIAN}

Hasil penelitian menunjukkan data karakteristik responden sebagai berikut:

Tabel 1. Karakteristik Jenis Kelamin dan Usia Responden serta Tingkat Pendidikan dan Pekerjaan Orangtua Responden Tahun 2020 ( $\mathrm{n}=28$ )

\begin{tabular}{|c|c|c|}
\hline Karakteristik Responden & Frekuensi & Prosentase (\%) \\
\hline Jenis kelamin & & \\
\hline Laki-laki & 20 & 71,42 \\
\hline Perempuan & 8 & 28,58 \\
\hline \multicolumn{3}{|l|}{ Usia } \\
\hline 4-5 tahun & 9 & 32,14 \\
\hline $5-6$ tahun & 19 & 67,86 \\
\hline
\end{tabular}




\section{Pekerjaan Orangtua}

Buruh

$\begin{array}{cc}7 & 25,01 \\ 12 & 42,85 \\ 1 & 3,57 \\ 8 & 28,57\end{array}$

Pedagang

2,85

Penjahit

28,57

\section{Tingkat Pendidikan Orangtua}

Tidak Sekolah

17,85

SD

5

17,85

SMP

5

SMA

12

21,45

Total

28

100

Sumber : Data Primer (2020)

Tabel 1. menunjukkan bahwa sebagian besar responden berjenis kelamin laki-laki $(71,42 \%)$ dan mayoritas responden berusia 5-6 tahun $(67,86 \%)$. Dilihat dari karakteristik orangtua, pekerjaan orangtua responden yaitu buruh, pedagang, penjahit dan petani, sedangkan tingkat pendidikan orangtua, 42,85\% adalah lulusan SMP.

Tabel 2. Perubahan Pengetahuan Responden Sebelum dan Setelah diberikan Art Therapy dengan Media Bermain Mewarnai Gambar dan Bercerita atau atau mendongeng Tahun $2020(\mathrm{n}=28)$

\begin{tabular}{cccccc}
\hline \multirow{2}{*}{ Pengetahuan } & \multicolumn{2}{c}{ Pretest } & \multicolumn{2}{c}{ Posttest } \\
\cline { 2 - 5 } & & $\sum$ & $\mathbf{\%}$ & $\sum$ & $\mathbf{\%}$ \\
\hline & Baik & 8 & 28,57 & 18 & 64,28 \\
\hline & Cukup & 3 & 10,71 & 8 & 28,57 \\
\hline Kurang & 17 & 60,72 & 2 & 7,15 \\
\hline
\end{tabular}

Sumber : Data Primer (2020)

Tabel 2 menunjukkan bahwa 60,72\% responden memiliki tingkat pengetahuan yang kurang tentang pemeliharaan kesehatan gigi, sebelum diberikan intervensi. Art therapy dengan metode bermain mewarnai gambar dan bercerita atau mendongeng efektif mampu meningkatkan pengetahuan responden, yaitu hanya $7,15 \%$ responden yang memiliki tingkat pengetahuan yang kurang setelah intervensi selesai diberikan. Hasil penelitian ini menunjukkan bahwa responden memahami tentang a) kapan waktu yang tepat untuk menggosok gigi, b) berapa kali frekuensi menggosok gigi per hari, c) pentingnya penggunaan pasta gigi, dan d) bagaimana akibat yang ditimbulkan jika malas menggosok gigi dengan pasta gigi.

Tabel 3. Perubahan Pemahaman Praktik Pemeliharaan Kesehatan Gigi Responden Sebelum dan Setelah diberikan Art Therapy dengan Metode Bermain Mewarnai Gambar dan Bercerita atau Mendongeng Tahun 2020 $(\mathrm{n}=28)$

\begin{tabular}{cccccc}
\hline Praktik Pemeliharaan & \multicolumn{2}{c}{ Pretest } & \multicolumn{2}{c}{ Posttest } \\
\cline { 2 - 5 } Kesehatan Gigi & $\sum$ & $\boldsymbol{\%}$ & $\sum$ & $\mathbf{\%}$ \\
\hline Baik & 7 & 25 & 13 & 46,44 \\
\hline
\end{tabular}




\begin{tabular}{cccccc}
\hline & Cukup & 6 & 21,42 & 9 & 32,14 \\
& Kurang & 15 & 53,58 & 6 & 21,42 \\
\hline Total & & 28 & 100 & 28 & 100 \\
\hline
\end{tabular}

Sumber : Data Primer (2020)

Berdasarkan tabel 3 menunjukkan bahwa 53,58\% responden memiliki tingkat pemahaman yang kurang tentang bagaimana praktik pemeliharaan kesehatan gigi yang benar, sebelum diberikan intervensi. Art therapy dengan media bermain mewarnai gambar dan bercerita atau mendongeng efektif mampu meningkatkan pemahaman responden, yaitu hanya $21,42 \%$ responden yang memiliki pemahaman yang kurang tentang bagaimana praktik pemeliharaan kesehatan gigi yang benar, setelah intervensi selesai diberikan.

Tabel 4. Hasil Analisis Uji Wilcoxon pada Variable Penelitian

\begin{tabular}{lccc}
\hline & $\mathrm{n}$ & $\begin{array}{c}\text { Median } \\
\text { (min - maks) }\end{array}$ & $p$ \\
\hline $\begin{array}{l}\text { Pengetahuan } \\
\text { Sebelum art therapy }\end{array}$ & 28 & $59(51-82)$ & 0,000 \\
$\begin{array}{l}\text { Setelah } \text { art therapy } \\
\text { Praktik Pemeliharaan Kesehatan Gigi }\end{array}$ & 28 & $80(53-86)$ & \\
$\begin{array}{l}\text { Sebelum art therapy } \\
\text { Setelah } \text { art therapy }\end{array}$ & 28 & $50(45-72)$ & 0,000 \\
\hline
\end{tabular}

Sumber: Data Primer (2020)

Berdasarkan tabel 4 , terdapat perbedaan pengetahuan yang bermakna $(p=0,000)$ antara sebelum dengan setelah pemberian art therapy. Selain itu, juga terdapat perbedaan pemahaman tentang praktik pemeliharaan kesehatan gigi yang bermakna $(p=0,000)$ antara sebelum pemberian intervensi dengan setelah pemberian intervensi.

\section{PEMBAHASAN}

Pada penelitian ini, 60,72\% responden memiliki tingkat pengetahuan yang kurang tentang pemeliharaan kesehatan gigi, sebelum diberikan intervensi. Hasil penelitian ini berkorelasi dengan tingkat pendidikan dan pekerjaan orang tua responden. Penanaman kebiasaan pada anak sangat dipengaruhi oleh tingkat pendidikan orangtua, semakin tinggi tingkat pendidikan orangtua dipercaya akan semakin mampu mengarahkan anak-anak pada kebiasaan yang baik (Yabanci et al, 2014). Peran serta orangtua sangat diperlukan dalam membimbing, memberikan pengertian, mengingatkan dan menyediakan fasilitas kepada anak agar anak dapat memelihara kesehatan gigi dan mulutnya dengan baik. Pengetahuan orangtua sangat penting dalam mendasari terbentuknya perilaku yang mendukung atau tidak mendukung terhadap kesehatan gigi dan mulut anak. Pengetahuan tersebut dapat diperoleh secara alami maupun secara terencana yaitu melalui proses pendidikan. 
Orangtua dengan pengetahuan yang kurang mengenai pemeliharaan kesehatan gigi dan mulut merupakan faktor predisposisi dari perilaku yang tidak mendukung pemeliharaan kesehatan gigi dan mulut anak yang optimal (Eddy et al, 2015). Dilihat dari karakteristik orangtua responden, pekerjaan orangtua responden pada penelitian ini adalah buruh, pedagang, penjahit dan petani, sedangkan tingkat pendidikan orangtua, 42,85\% adalah lulusan SMP. Hasil penelitian ini didukung oleh Dikshit et al, (2018) bahwa tingkat pendidikan dan pengetahuan orangtua berpengaruh secara adekuat terhadap sikap dan perilaku orangtua dalam membentuk kebiasaan anak-anak. Hanya 56,5\% orangtua yang menanamkan kebiasaan gosok gigi dengan pasta gigi pada anak mereka, dengan alasan takut dan khawatir pasta gigi akan tertelan. Hasil ini menunjukkan bahwa tingkat pendidikan dan pengetahuan yang kurang tentang pemeliharaan kesehatan gigi anak. tingkat pendidikan dan pengetahuan orangtua berbanding lurus terhadap status kesehatan gigi anak karena anak-anak mulai belajar secara dini di lingkungan rumah mereka, dan orangtua memegang peranan penting dalam penanaman kebiasaan kesehatan gigi yang optimal bagi anak-anak.

Berdasarkan hasil penelitian ini, art therapy dengan metode mewarnai gambar dan bercerita atau mendongeng terbukti berpengaruh positif terhadap tingkat pengetahuan responden tentang bagaimana pemeliharaan kesehatan gigi yang tepat ( $p$ value $<0,05)$. Responden antusias, senang dan aktif mendengarkan cerita atau dongeng yang disampaikan oleh guru, melalui tokoh yang diceritakan dalam dongeng pada buku cerita, responden dapat mempelajari serta menganalisa sebab akibat apabila tidak memelihara kesehatan gigi dengan baik. Hasil penelitian ini didukung oleh Isik (2016) bahwa bercerita atau mendongeng memberikan dampak positif terhadap perkembangan kognitif anak.

Kegiatan mendongeng lebih efektif dan akan lebih memperluas pengenalan objek apabila saat mendongeng juga menggunakan alat peraga misalnya buku cerita bergambar, sehingga anak bisa melihat bentuk dari tokoh yang diceritakan dalam dongeng tersebut. Selain itu, dongeng juga dapat menambah wawasan, melalui kisah-kisah dongeng, anak mendapatkan berbagai informasi dan anak juga dapat mempelajari sebab akibat serta belajar menganalisa. Metode mendongeng juga membentuk pemikiran anak menjadi lebih baik, lebih kritis dan cerdas, anak juga bisa memahami hal-hal mana yang boleh dan tidak boleh ditiru. Bercerita atau mendongeng juga efektif mengembangkan daya imajinasi anak, meningkatkan ketrampilan berbahasa dan membangkitkan minat baca anak. Bercerita atau mendongeng juga membentuk retensi pengetahuan yang lebih baik sehingga anak-anak mempunyai memori yang tajam terhadap pembelajaran yang dilakukan. Pembelajaran dengan metode bercerita atau mendongeng memerlukan pemanasan terlebih dahulu dari guru/pendamping atau orangtua, misalnya dengan bertanya dan meminta anak-anak bercerita tentang pengalamannya terkait tema yang akan kita bahas. Vaahtoranta et al (2019) juga memaparkan hal yang sama bahwa bercerita atau mendongeng memberikan efek positif terhadap kemampuan daya ingat anak usia prasekolah. Bercerita atau mendongeng dengan dapat meningkatkan daya ingat, meningkatkan kemampuan anak dalam menerima konsep/teori baru dan 
mampu merubah perilaku anak secara perlahan sehingga metode ini sangat disarankan diaplikasikan pada anak usia prasekolah, baik dirumah dengan pendampingan orangtua dan juga di sekolah dengan pendampingan guru. Pada penelitian ini, responden dengan mudah memahami tentang a) kapan waktu yang tepat untuk menggosok gigi, b) berapa kali frekuensi menggosok gigi per hari, c) pentingnya penggunaan pasta gigi, dan d) bagaimana akibat yang ditimbulkan jika malas menggosok gigi dengan pasta gigi. Responden senang, aktif dan ekspresif dalam mewarnai gambar-gambar mereka, dan responden mewarnai gambar dengan warna-warna pilihan mereka yang merupakan warna kesukaan mereka. Melalui pesan cerita yang disampaikan melalui aktivitas mewarnai gambar ini, responden mudah dan senang dalam belajar tentang bagaimana pemeliharaan kesehatan gigi. hal ini senada dengan yang disampaikan Alvina dan Kurnianingrum (2018), bahwa penggunaaan aktivitas seni menggunakan metode menggambar dan mewarnai (visual art) sebagai terapi merupakan bentuk komunikasi yang jarang dilakukan resistensi atau penolakan oleh anak-anak dan memberi anak-anak cara baru mengekspresikan pikiran dan perasaannya. Shofiyah (2013) juga menambahkan bahwa pada dasarnya anak-anak sangat menyukai dan menikmati pembelajaran dengan metode mewarnai gambar (visual art).

Selain berpengaruh positif terhadap tingkat pengetahuan, art therapy dengan metode mewarnai gambar dan bercerita atau mendongeng juga terbukti berpengaruh positif terhadap kemampuan praktik atau skill responden dalam pemeliharaan kesehatan gigi ( $p$ value $<0,05)$. Pada penelitian ini, responden dengan mudah memahami tentang bagaimana teknik dan tahapan-tahapan menggosok gigi yang benar serta cara meletakkan atau menyimpan sikat gigi setelah selesai dipergunakan. Tingkat pengetahuan responden tentang pemeliharaan kesehatan gigi berbanding lurus dengan kemampuan praktik atau skill responden. Hasil penelitian ini didukung oleh Lestari (2019) bahwa tindakan atau praktik perilaku merupakan respon individu terhadap suatu stimulus. Pengetahuan merupakan stimulus yang dapat meningkatkan kemungkinan individu melakukan suatu tindakan atau praktik perilaku, semakin baik pengetahuan individu terhadap sesuatu maka semakin meningkat juga kemungkinan individu melakukan tindakan atau praktik perilaku tersebut. Aminimanesh et al (2018) juga menjelaskan hal yang sama bahwa art therapy dengan metode bercerita atau mendongeng efektif memberikan perubahan perilaku pada anak usia prasekolah. Saat guru selesai bercerita atau mendongeng, anak-anak akan menyadur atau menceritakan ulang konten/isi cerita serta menganalisis bagaimana jalannya cerita, kemudian anak-anak akan mudah mengikuti atau menirukan tindakan atau praktik perilaku tokoh yang diceritakan dalam dongeng tersebut.

\section{KESIMPULAN}

Optimalisasi promosi kesehatan tentang pemeliharaan kesehatan gigi pada anak usia prasekolah dapat diaplikasikan melalui penerapan art therapy. Art therapy melalui metode mewarnai gambar dan 
bercerita atau mendongeng terbukti efektif meningkatkan pengetahuan dan praktik pemeliharaan kesehatan gigi pada anak usia 4-6 tahun.

\section{DAFTAR PUSTAKA}

Alvina, Kurnianingrum, W. (2018). Penerapan Art Therapy Untuk Meningkatkan Self-Esteem Anak Usia Middle Childhood. Jurnal Muara Ilmu Sosial, Humaniora Dan Seni, 2(1), 198-204.

Angelisa, A. (2014). Pengaruh Pendidikan Kesehatan Gosok Gigi dengan Metode Bermain terhadap Perilaku Gosok Gigi pada Anak Usia Prasekolah di TK ABA Wilayah Wonokromo Pleret Bantul. Program Studi Ilmu Keperawatan. STIKES Aisyiyah Yogyakarta.

Aminimanesh, A., Ghazavi, Z., Mehrabi, T. (2018). Effectiveness of the Puppet Show and Storytelling Methods on Children's Behavioral Problems. Iranian Journal of Nursing and Midwifery Research. 24, 61-65

Arini, T., Haryanti, F., \& Prabowo, T. (2016). Pengaruh Promosi Kesehatan Perilaku Hidup Bersih dan Sehat terhadap Tingkat Pengetahuan dan Perilaku Hidup Bersih dan Sehat pada Siswa SD di Wilayah Kerja Puskesmas. Jurnal Ilmu Keperawatan, 1(3), 118-122.

Ardani, I. G. (2018). Buku Kesehatan Anak untuk Orang Tua Gigi Sehat, Anak Cerdas (pp. 231-233). Yogyakarta: CV. Budi Utama.

Brouzos, A, Vassilopoulos, SP, Moschou, K. 2016. Utilizing Storytelling to Promote Emotional WellBeing of Children With a Distinct Physical Appearance: The Case of Children Who Wear Eyeglasses. The European Journal of Counselling Psychology. 4(1), 62-76

Debora, Arisska, Sitompul, \& Relina, D. (2012). Pengaruh Terapi Mewarnai Gambar dengan Pasir Warna Terhadap Kecemasan Anak Prasekolah 3-5 Tahun. Skripsi. STIKES Suaka Insan Banjarmasin.

Dikshit, P, Limbu, S, Gupta, S, Pradhan, R. (2018). Evaluation of Knowledge, Attitude and Practices of Parents Toward Their Children's Oral Health Compared With Their Dental Caries Status. Birat Journal of Health Sciences. 3(2), 447-452

Eddy, F. N. A. E., \& Mutiara, H. (2015). Peranan Ibu dalam Pemeliharaan Kesehatan Gigi Anak dengan Status Karies Anak Usia Sekolah Dasar. Majority, 4(8), 4-9.

Elmitra. (2017). Dasar -Dasar Farmasetika dan Sediaan Semi Solid. Yogyakarta: CV. Budi Utama.

Hidayat, D. R. (2018). Konseling Di Sekolah: Pendekatan-Pendekatan Komtemporer. Jakarta: Prenadamedia Group.

Hannigan, S., Grima-Farrel, C., Wardman, N. (2019). Drawing on creative arts therapy approaches to enhance inclusive school culturs and student wellbeing. Issue in Educational Research. 29(3), 756773

Isik, M.A. (2016). The Impact of Storytelling on Young Ages. European Journal of Language and Literature Studies. 2(3), 115-118

Kurniasih, T. (2018). Sistem Organ Manusia (pp. 300-343). Yogyakarta: CV. Budi Utama.

Ramayanti, S., \& Purnakarya, I. (2013). Peran makanan terhadap kejadian karies gigi. Jurnal Kesehatan Masyarakat, 7(2), 89-93.

Santik, Y. D. P. (2015). Pentingnya Kesehatan Gigi dan Mulut dalam Menunjang Produktivitas Atlet. Jurnal Media Ilmu Keolahragaan Indonesia, 5(1), 13-17.

Sari, EK, Ulfiana, E, Dian, P. (2019). Pengaruh Pendidikan Kesehatan Gosok Gigi dengan Metode Permainan Simulasi Ular Tangga terhadap Perubahan Pengetahuan, Sikap, dan Aplikasi Tindakan Gosok Gigi Anak Usia Sekolah di SD Wilayah Paron Ngawi. Indonesian Journal of Community Health Nursing, 1(1), 1-11.

Senjaya, A. (2019). Menyikat Gigi Tindakan Utama Untuk Kesehatan Gigi. Jurnal Gema Keperawatan, $12(2), 14-22$.

Shofiyah. (2013). Penerapan Pembelajaran Mewarnai Gambar Dalam Meningkatkan Motorik Halus Anak Kelompok B Di TK Hidayatus Shibyan. Universitas Negeri Surabaya. 
Triswari, D., \& Pertiwi, A. D. (2017). Pengaruh Kebiasaan Menyikat Gigi Sebelum Tidur Malam Terhadap Skor Indeks Plak dan pH Saliva. Insisiva Dental Journal, 6(2), 1-8

Widayati, N. (2014). Faktor yang Berhubungan dengan Karies Gigi pada Anak Usia 4-6 Tahun. Berkala Epidemiologi, 2(2), 196-205.

Winnier, JJ., Parmar, A., Mehta, S., Bambal, K., Bhatia, R. (2019). Oral Hygiene Maintenance in Children-A Survey of Parental Awareness. International Journal of Oral Health and Medical Research. Vol. 2(4), 1-5

Vaahtoranta, E., Lenhart, J., Suggate, S., Lenhard, W. (2019). Interactive Elaborative Storytelling: Engaging Children as Storytellers to Fosters Vocabulary. Frontiers in Psychology. 10, 1534-1547

Yabanci, N., Kisac, I., Karakus, S.S. 2014. The Effects of Mother's Nutritional Knowledge on Attitudes and Behaviors of Children about Nutrition. Procedia - Social and Behavioral Sciences. 116, 44774481 